\title{
Importância da pesquisa e desenvolvimento de foguetes e propulsão
}

$\mathrm{D}$ iante da diversidade de assuntos abordados no mundo das ciências exatas, com certeza um deles, construir ou trabalhar com um grupo que constrói foguetes, instiga muito a curiosidade de muitos desde criança. Até recentemente essas possibilidades eram prejudicadas pelo desconhecimento e pela falta de oportunidade fazendo com que muitos entusiastas optassem por seguir outros caminhos da engenharia, física e áreas correlatas. No entanto, esse segmento possui grande importância sendo considerado de conhecimento estratégico. No entanto, por que estudos em propulsão de foguetes seriam tão importantes? Qual seria o papel da iniciativa privada?

Olhando para o passado, as primeiras propostas de foguetes ou sistemas de propulsão começaram a tomar forma no início do século XX com pesquisas isoladas pelo mundo feitas por Konstantin Tsiolkovsky (1857-1935), um professor e pioneiro russo, Robert H. Goddard (1882-1945), físico norte-americano, que inventou um propulsor com combustível ou propelente líquido, e o físico alemão Hermann Oberth (1894-1989). Essas pesquisas preliminares serviram de base para o desenvolvimento de mísseis balísticos na Segunda Guerra Mundial, gerando muita resistência no período pós-guerra. Países que detinham a tecnologia, como Alemanha, EUA e Rússia mostravam resistência a novas iniciativas de outros países, por duvidarem que essas fossem realizadas para fins pacíficos.

Quando dotados de instrumentação dedicada, a mesma tecnologia pode ser empregada para fazer pesquisas científicas, pois necessariamente os foguetes precisam voar acima da atmosfera terrestre, o que justifica sua aplicação. Importante referir que a fronteira entre a atmosfera e o espaço se encontra a $100 \mathrm{~km}$ em uma região chamada de Linha de Karman. Fenômenos relacionados ao espaço, como a influência de campos gravitacionais, radiação eletromagnética, raios cósmicos e campos magnéticos de distribuição desconhecida, só podem ser estudados sem as distorções da atmosfera terrestre.

Os sistemas de propulsão são assim chamados por seguirem a Terceira Lei de Movimento de Newton, a Lei de Ação e Reação. Assim um dispositivo lança uma massa em uma direção, sob a forma de jato de exaustão proveniente de gases de combustão, através de um bocal bastante estreito, acelera o sistema na direção oposta. Um sistema de propulsão pode ser comparado a

Pontifical Catholic University of Rio Grande do Sul Porto Alegre, RS, Brazil

Editor

Thais Russomano

Microgravity Center PUCRS, Brazil

Executive Editor

Rafael Reimann Baptista

Faculdade de Educação Física e Ciências do Desporto, PUCRS, Brazil

e-ISSN: 2179-703X
Corresponding Author:

Luciano Hennemann

<elhennemann@gmail.com>

Received: January 20, 2016 Accepted: January 21, 2016

(C) 2016 EDIPUCRS

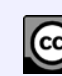

his work is licensed under a

Creative Commons-Attribution 4.0 International. http://creativecommons.org/licenses/by/4.0/ 
um motor, possibilitando que um veículo espacial altere sua posição, velocidade e orientação no espaço.

Os sistemas mais usados têm natureza química e podem ser bipropelentes ou monopropelentes. Nos bipropelentes, é utilizado um combustível e um oxidante, que podem ser sólidos, líquidos ou gasosos, os quais são injetados e misturados em uma câmara. Esses sofrem combustão, através de reação química, e a energia é liberada pelo bocal, gerando o empuxo. Eles são utilizados em missões com elevado empuxo (em torno de $1,2 \times 10^{7} \mathrm{~N}$ ), onde a carga útil é transportada da superfície terrestre para fora da atmosfera. Suas estruturas são robustas, pois necessitam suportar as intempéries do percurso e vencer a resistência da atmosfera. Em torno de 95\% do peso total do equipamento, é compreendido de tanques de propelentes e o sistema de propulsão, sendo apenas $5 \%$ do peso considerado como carga útil. Nos sistemas de propulsão monopropelentes, a energia gerada é produzida pela decomposição de apenas um propelente. Eles possuem um empuxo menor (até $500 \mathrm{~N}$ ) e são usados para posicionamento e controle de atitude em dispositivos que se encontram fora da atmosfera. Existem, ainda, sistemas de propulsão elétrica (empuxo até $10 \mathrm{~N})$, menos comuns e com aplicações específicas. A pesquisa desses sistemas é mais recente e normalmente são destinados para deslocamentos de objetos no espaço.

Portanto, esses sistemas são responsáveis pela colocação em órbita e pelo posicionamento, principalmente, de satélites com fins científicos ou operacionais. Pelo fato desse conhecimento ser estratégico e caro, assegura um grande domínio tecnológico e divisas, pois os países cobram dos que não possuem essa tecnologia preços elevados para colocarem objetos no espaço. No entanto, gradativamente com o surgimento de novos tratados, aumento de confiança e uma dose de coragem, novos estudos com sistemas de propulsão capazes de atingir elevadas altitudes na atmosfera foram iniciados e um novo conhecimento vem sendo desenvolvido sobre a Terra, os planetas e o espaço. Países como Japão, China, Índia e União Europeia criaram novos programas, com uma diversidade de missões, permitindo avanços científicos importantes que são trazidas ao cidadão comum através de novos sistemas de telecomunicações e de navegação, estudos do clima, previsão do tempo e avanços na área de biomedicina, entre outros.

No Brasil, o Instituto Nacional de Pesquisas Espaciais (INPE) emprega, com sucesso, sistemas de propulsão para aplicação em correção de órbitas, posicionamento e controle de atitude embarcado em satélites. Ele produz, também, pesquisas e testes com novos propelentes (como o óxido nitroso, peróxido de hidrogênio, etanol, etanolamina), buscando alternativas pioneiras as existentes (hidrazina, tetróxido de nitrogênio), devido à disponibilidade de oferta no mercado de fornecedores, periculosidade no manuseio e toxidez. Entretanto, o Brasil sempre evidenciou interesse em desenvolver seu próprio veículo lançador. Para tanto, iniciativas são produzidas por instituições governamentais brasileiras, exemplo da NASA e ESA no exterior.

A Agência Espacial Brasileira (AEB) coordena as atividades no setor aeroespacial e a sua execução ocorre através do INPE, o Instituto Tecnológico da Aeronáutica (ITA) e também o Instituto de Aeronáutica e Espaço (IAE). Entretanto, em termos históricos, os programas nacionais são ofuscados, especialmente em períodos de dificuldades, quando recursos dessas instituições diminuem, levando consigo parte da motivação de todos aqueles que estão inseridos no contexto. Atualmente, percebe-se uma grande motivação de grupos privados, um tanto inquietos com o que vem surgindo em outros países emergentes e, também, em razão das demandas do mercado interno. Isto tem afetado positivamente as instituições de ensino, principalmente as privadas, gerando oferta de cursos relacionados a sistemas de propulsão de foguetes, realimentando, positivamente, o segmento no cenário brasileiro.

Novas iniciativas no desenvolvimento em sistemas de propulsão, de um modo geral, oportunizam ao país colocar em órbita cargas úteis para pesquisas de interesse pacífico, abrindo uma cadeia de novos horizontes em outras áreas, ainda ocultas e inacessíveis. Benefícios interessantes podem ser disponibilizados para a sociedade brasileira, como, por exemplo, novos serviços em telecomunicações, melhoria nos sistemas de navegação e nas atividades de geoprocessamento, refinamento na monitoração das fronteiras, das florestas e queimadas, avanços no gerenciamento de recursos naturais, no estudo do comportamento do clima e 
pesquisas na área biomédica, bem como a facilitação do envio de objetos para pesquisas em longas distâncias. Além desses, outros benefícios podem ser contabilizados por meio de ganhos financeiros para o Brasil, tanto na prestação e venda de serviços relacionados como na afirmação de empresas privadas voltadas à produção de propulsores semelhante ao que ocorre no exterior (SpaceX, Virgin Galactic). A nova geração de pesquisadores poderá desfrutar do avanço das pesquisas nessa área, inserindo o Brasil, de forma mais definitiva, no contexto internacional, nas pesquisas em novos segmentos do setor espacial, somando-os aos gêneros onde atualmente já é referência. 